\title{
Significant Learning in Renewable Energy
}

\section{Dr. Timothy L Marbach, California State University Sacramento}

Dr. Timothy Marbach is an Associate Professor of Mechanical Engineering at California State University Sacramento, where he teaches courses in thermodynamics, thermal-fluid systems and project engineering. Tim received his Bachelors degree from St. Mary's University in San Antonio, Texas and Ph.D. from the University of Oklahoma in Norman. He has received the Outstanding Teaching Award for the CSUS College of Engineering and Computer Science and the Tau Beta Pi California Upsilon Chapter's Outstanding Teaching Award. His research interests include thermochemical processing of biofuels, combustion and applied energy/heat recovery. 


\section{Significant Learning in Renewable Energy}

Significant learning in engineering education

For over 50 years, Bloom's taxonomy has been used widely in higher education, including engineering, as a foundation of effective pedagogy ${ }^{1}$. The taxonomy has three domains: cognitive, affective and psychomotor. Higher education typically emphasizes the cognitive domain, which is summarized in Table 1.

\begin{tabular}{|l|l|}
\hline \multicolumn{2}{|c|}{ Table 1. Summary of Bloom's Taxonomy - Cognitive } \\
\hline \multicolumn{1}{|c|}{ Level } & \multicolumn{1}{c|}{ Example Action Verbs } \\
\hline Knowledge & Define, list, match, name, recall \\
\hline Comprehension & Classify, estimate, paraphrase, summarize \\
\hline Application & Apply, compute, predict, solve, use \\
\hline Analysis & Analyze, compare, contrast, categorize, outline, model \\
\hline Synthesis & Assemble, construct, formulate, synthesize \\
\hline Evaluation & Appraise, argue, conclude, judge, value \\
\hline
\end{tabular}

Variations of Bloom's taxonomy have been developed and used through the years. One such variation is provided by Fink in Creating Significant Learning Experiences: An Integrated Approach to Designing College Courses ${ }^{2}$. In this paper, the term "significant learning" is used in relation to the methodology described by Fink. A summary of the modified taxonomy (referred to as Fink's taxonomy through the remainder of this paper) is provided in Table 2.

\begin{tabular}{|l|l|}
\hline \multicolumn{2}{|c|}{ Table 2. Summary of Fink's Taxonomy of Significant Learning ${ }^{2}$} \\
\hline \multicolumn{1}{|c|}{ Level } & \multicolumn{1}{c|}{ Example Action Verbs } \\
\hline Foundational Knowledge & Define, list, match, name, recall \\
\hline Application & Organize, rank, solve, calculate, prove \\
\hline Integration & Compare, contrast, correlate, integrate \\
\hline Human Dimension & Advise, influence, motivate, mediate, communicate \\
\hline Caring & Commit, discover, value \\
\hline Learning how to Learn & Develop a learning plan, identify resources, research \\
\hline
\end{tabular}

Several key differences in Fink's taxonomy should be noted.

- Bloom's knowledge and comprehension levels are combined in Fink's foundational knowledge level.

- Fink's definition of application is broader than Bloom's, since it includes much of the analysis level described in Bloom.

- The integration level adds an interdisciplinary dimension, including the relationships between ideas, objects, etc.

- The human dimension and caring levels bring in aspects from Bloom's affective domain, which is not often considered when using Bloom's taxonomy to design courses.

- The learning how to learn realm addresses lifelong learning, a concept that has been increasingly emphasized in recent years. 
Traditionally, engineering education has focused on lower levels of learning within Fink's taxonomy, such as foundational knowledge and application. Recently, higher levels of learning have received increased attention with widespread use of team-based, problem-based and experiential learning ${ }^{3-7}$. Fink's significant learning approach to course design goes beyond just the taxonomy. Significant learning uses "integrated course design," which focuses on the relationships between three key aspects of any course: learning goals, teaching and learning activities and feedback and assessment. Another key aspect of his significant learning approach is to use "rich learning experiences," those that combine multiple learning levels into one activity. A description of how the significant learning approach was applied to the renewable energy course is presented in the learning goals and teaching and learning activities sections later in this paper.

Renewable energy curriculum

Energy sustainability is one of the most significant challenges facing the current generation of engineering graduates ${ }^{8-10}$. Engineers are tasked with meeting the tremendous energy demand of the world's growing, industrializing population while simultaneously reducing climate change and air pollution. Additionally, the socioeconomic and national security implications of the energy solutions that will be developed over the next several decades are tremendous. Thus, it is critical for engineers to understand the magnitude of the energy problem and to be prepared to contribute solutions as they enter the profession.

At California State University Sacramento (CSUS), the fundamentals of energy are covered in the thermal-fluids area. The required courses in this area are described below.

- Thermodynamics - Study of thermodynamic principles and their applications to engineering problems. Includes a study of the first and second laws, the properties of pure substances and ideal gas, gas/vapor mixtures, and an introduction to thermodynamic cycles.

- Fluid Mechanics - Lectures and problems in the fundamental principles of incompressible and compressible fluid flow.

- Heat Transfer - Basic principles of heat transfer, including processes of conduction, convection, radiation, evaporation and condensation.

- Thermal-Fluid Systems - Fundamentals of power cycles, refrigeration, psychrometric processes and chemical reactions. Theory and application of temperature, pressure, flow, and velocity instruments, introduction to experiment design, errors, uncertainty and data acquisition.

Each student should be competent in these fundamental areas after completing the four thermalfluids courses. However, in order to fully prepare students to enter the rapidly growing renewable energy field, electives were needed. Originally, one three-unit elective called Renewable Energy Systems was developed and offered from 2005 to 2010. The topics of the course included wind, solar thermal, geothermal, hydro, tidal, wave and bioenergy. While the course was successful, it did not provide sufficient depth into any one area. So, the material was expanded and divided into the following courses (2-units each) beginning in 2011. 
Solar thermal and energy storage

Wind, wave, hydro and tidal power

Geothermal and bioenergy

Fink's significant learning approach was applied to the solar thermal and energy storage course offered in fall 2013. The situational factors, learning goals, teaching and learning activities and feedback and assessment for this course are presented below.

Situational factors

The solar thermal and energy storage course at CSUS is a senior elective, which typically has an enrollment of 15-25. In fall 2013, the course had 17 students (15 seniors and 2 graduate students). All students had completed thermodynamics and fluid mechanics. However many students take heat transfer and thermal-fluid systems during their final semester as undergraduates. So, several students took this elective and heat transfer and/or thermal-fluid systems simultaneously. The variety of backgrounds regarding heat transfer and thermal-fluid systems was the greatest challenge in designing the course. The course met one day per week for 100 minutes over a 15 -week semester. Topics of the course included the solar resource, solar collectors, solar thermal power, thermal energy storage, phase change materials, pumped hydro, compressed air storage and flywheels.

\section{Course Learning Goals}

Each of the learning goals presented below address a different level within Fink's taxonomy. The corresponding level in Fink's taxonomy is presented in parentheses at the end of each learning objective.

By the end of the course, students will be able to:

1. Explain important ideas and concepts of solar thermal and energy storage systems to a colleague. (foundational knowledge)

2. Formulate, solve, and analyze real-world solar thermal and energy storage problems with a methodological, systematic approach based on the physical laws at the heart of each technology. This includes analyzing the performance, efficiency, economics and risks of each technology. (application)

3. Connect the principles and techniques learned in this course with other subjects and use these principles and techniques to solve multi-disciplinary engineering problems. (integration)

4. Value sustainability and recognize the importance and necessity of clean and sustainable energy. (caring)

5. Identify and locate sources of information related to solar thermal and energy storage systems and apply the information to complete an authentic project. (learning how to learn)

The human dimension was an important aspect with the numerous team activities in the course, but it was not explicitly stated as a learning objective. 
A wide range of teaching and learning activities were used in the course. Each activity is described below, along with the levels of learning that each activity was designed to address.

- Readings, Readiness Assessment Tests (RATs) and Class Discussions - During a typical week, the students were assigned a reading to be completed before class. These readings came from a range of sources, typically highlighted sections from review papers published in scholarly journals, such as Applied Energy ${ }^{11}, \underline{\text { Renewable and Sustainable }}$ Energy Reviews $^{12-14}$, and Progress in Energy and Combustion Science ${ }^{15}$. At the beginning of each class, the students took a RAT, a short quiz to assess their understanding of the material. The RATs were designed with the first question or two to be very simple, anyone that completed the reading should be able to answer correctly. The last question or two were more difficult, with a more thorough understanding required for a correct answer. The RATs served several purposes. First, they motivated the students to read because they made up a significant portion of their grade. Second, it gave the students and the instructor quick feedback on their comprehension of each reading. Finally, the questions on each RAT served as an outline for the class discussion regarding each reading. That is, the class and instructor would discuss each question, correct and incorrect answers, and other topics in the readings that relate to each RAT question. Completion of the RAT itself was very quick, typically 5-7 minutes, but the class discussions were more lengthy, typically 20 minutes. These activities targeted foundational knowledge and human dimension learning.

- Team Presentations and Wiki - Occasionally, brief team presentations were used in lieu of RATs. Students would arrive to class expecting to take a RAT. Instead, they would get into their teams and have 10 minutes to create a brief summary of a section of the reading. Teams were assigned by the instructor, with at least two students who had completed heat transfer in each team. They could use the board or large poster-sized paper to organize their thoughts. Then, each team would present their summary to the class ( 5 minutes per team). These team presentations introduced the human dimension learning, enhancing their understanding of the material through their interactions with each other. After class, each team was required to post an outline of important information from their section on the class wiki.

- Lectures and Example Calculations - Following the RAT, in-depth lecture material and examples were presented by the instructor. The lectures focused on connecting the fundamental principles of heat transfer, fluid mechanics, or thermodynamics with the state-of-the-art technology used in industry today. The lectures used a mixture of PowerPoint slides, problem-solving on the white board and physical visual aids (such as an evacuated tube solar collector). The beginning of each lecture focused on adding depth to the topic of the previous reading and the end of each lecture introduced the topics of the next reading. The example problems introduced the techniques that the students would use to complete their homework and team projects. The primary focus of the lectures and examples were foundational knowledge and application. However, most examples were designed to elicit the caring level as well. This was usually achieved by 
taking the example one step further than usual. For example, the result of a particular example was an extremely large solar collector area needed to replace a combined cycle power plant with a solar trough system. Rather than just "box the answer" and move on. The area was overlaid over a Google-Maps image of the CSUS campus. When calculating the flow rate through a large pumped hydro system delivering a significant amount of power, the units were converted from cubic meters per second to Olympic sided swimming pools per minute. This helped the students relate to these results and get a sense of the magnitude of the systems.

- YouTube Videos - At the end of each major section, the class watched and discussed several YouTube videos showing current developments and products. These videos and discussions helped solidify students' understanding of the technology and the students were able to compare, contrast and criticize the various technologies and applications. The videos were used to enhance foundational knowledge, integration and caring.

- Homework - Sample problem sets, along with written (pdf) and video solutions were provided. Homework was not collected or graded. Like the in-class examples, application was the primary focus of this activity, but the problems were designed with caring in mind, as described in the lectures and example calculations section.

- Team Project and Team Project Review - At the end of the solar thermal section and again at the end of the energy storage section, the teams completed an open-ended design project. Each team wrote a brief proposal for their project that was then modified or clarified by the instructor. For example, a team might choose to design a solar-thermal space-heating system for a multi-family dwelling at a certain location. The team then located and obtained radiation data, weather data, heating load information, and they built an energy balance model using efficiency curves from actual solar collectors on the market. They performed parametric studies of different designs and conditions. They then drew conclusions and recommended a certain collector type (product), area (number of modules), storage media and size, etc. After the project reports were submitted, the teams completed a blind review and ranked the other project reports, providing feedback to the other teams in the form of strengths and weaknesses. The team projects brought together several types of learning. Application learning was needed for the calculations. However, integration learning was more significant, since the students were required to compare and contrast various options or technologies in their projects. Human dimension and learning how to learn types were also very significant.

- Guest Lecture - Two engineering supervisors from a local utility with both solar thermal power and various forms of energy storage gave a presentation and answered questions. The guest lecture hit many levels of learning, with caring being the most significant.

- Individual Presentation - The students made a brief presentation on a detailed aspect of solar thermal or energy storage technology (i.e. selective surface coatings, materials used for flywheels, a particular pumped hydro facility). This activity focused on learning how to learn and human dimension learning. 
- Exams - Two exams were given, one for solar thermal and another for energy storage. Half of the points for each exam focused on qualitative aspects and the other half on quantitative.

The following percentages were used for student grading.

$\begin{array}{ll}\text { RATs } & 20 \% \\ \text { Team Projects } & 20 \% \\ \text { Individual Presentation } & 20 \% \\ \text { Exams (2) } & 40 \%\end{array}$

Feedback and Assessment

Detailed questionnaires were used to assess how well the students met the learning goals of the course and to determine the effectiveness of each of the learning activities from the students' perspectives. One questionnaire was completed after the solar thermal module and another after energy storage. Results are presented in Tables 3 and 4.

The first sections of Tables 3 and 4 present the students' perceptions of how well they met the learning goals of the course. The scores ranged from a low of 7.2 to a high of 8.7 out of 10.0. Overall, the students' perceptions were consistent with their performance on the exams with one exception. The average score on the solar-thermal calculation portion of the exam was over $85 \%$, compared to the lower average score of $79 \%$ for the solar-thermal qualitative questions. Students rated their abilities to solve solar thermal problems low (7.2) compared to their abilities to explain the fundamentals of solar thermal energy (8.1).

The second sections of Tables 3 and 4 present the effectiveness of each learning activity as it contributed to foundational knowledge learning from the students' perspective. Class lectures were the most effective activities in both modules for this type of learning. The guest lecture was also effective. Interestingly, the readings and RATs were rated among the least effective, while the class discussions (which often stemmed out of the RATs) were rated highly. The wiki and YouTube videos were rated relatively low and they had the highest standard deviation of all of the learning activities. Some students rated them very highly, while others low. It should be noted that that in general the in-class activities rated highly, while the out of class activities rated lower.

The third sections of Tables 3 and 4 present the effectiveness of various learning activities for promoting application learning. The in-class examples and practice problems with solutions were most effective. Interestingly, the in-class examples were rated as the most effective learning activity overall, while the students rated their abilities to solve problems related to solar thermal energy the lowest. The final section of Tables 3 and 4 shows that the team projects were moderately effective in promoting learning-how-to-learn, with scores of 8.1 and 7.3. 


\begin{tabular}{|c|c|c|}
\hline Question & $\begin{array}{l}\text { Average } \\
\text { Response }\end{array}$ & $\begin{array}{c}\text { Standard } \\
\text { Deviation }\end{array}$ \\
\hline \multicolumn{3}{|l|}{ Rate how well you achieved the following learning goals on a scale of $1-10(1=$ no ability and $10=$ mastery $)$. } \\
\hline $\begin{array}{l}\text { Explain the solar radiation resource, including the characterization of solar radiation, the } \\
\text { various angles, data collection and use. }\end{array}$ & 7.6 & 1.5 \\
\hline $\begin{array}{l}\text { Explain how the various types of solar thermal collectors, their features, and identify their } \\
\text { suitability for various applications. }\end{array}$ & 8.5 & 1.0 \\
\hline Explain the ways that power can be produced using solar thermal energy. & 8.1 & 0.9 \\
\hline Formulate, solve, and analyze real-world solar thermal problems. & 7.2 & 1.6 \\
\hline $\begin{array}{l}\text { Identify and locate sources of information related to solar thermal and energy storage systems } \\
\text { and apply the information to complete an authentic project. }\end{array}$ & 7.8 & 1.4 \\
\hline \multicolumn{3}{|c|}{$\begin{array}{l}\text { On a scale of } 1 \text { (none) to } 10 \text { (a great amount), rate how well each of these learning activities contributed to your } \\
\text { foundational knowledge regarding solar thermal energy. }\end{array}$} \\
\hline Readings & 7.6 & 1.9 \\
\hline Quizzes on the Readings & 6.5 & 1.9 \\
\hline Class Discussions & 8.8 & 0.9 \\
\hline Lectures by Instructor & 8.8 & 0.9 \\
\hline Student Presentations (yours/others) & 7.5 & 1.6 \\
\hline Creating/Using the Wiki & 6.8 & 2.3 \\
\hline YouTube Videos & 7.4 & 2.4 \\
\hline Team Project & 8.1 & 2.0 \\
\hline Team Project Review & 7.5 & 1.7 \\
\hline \multicolumn{3}{|c|}{$\begin{array}{l}\text { On a scale of } 1 \text { (none) to } 10 \text { (a great amount), rate how well each of these learning activities contributed to your ability to } \\
\text { formulate, solve and analyze solar thermal energy problems. }\end{array}$} \\
\hline Examples and Lectures & 9.2 & 0.8 \\
\hline Team Project & 8.1 & 1.6 \\
\hline Team Project Review & 6.9 & 1.5 \\
\hline \multicolumn{3}{|c|}{$\begin{array}{l}\text { On a scale of } 1 \text { (none) to } 10 \text { (a great amount), rate how well each of these learning activities contributed to your ability to } \\
\text { identify, locate and use sources of information related to solar thermal energy. }\end{array}$} \\
\hline Team Project & 8.1 & 1.7 \\
\hline
\end{tabular}




\begin{tabular}{|c|c|c|}
\hline Question & $\begin{array}{l}\text { Average } \\
\text { Response }\end{array}$ & $\begin{array}{c}\text { Standard } \\
\text { Deviation }\end{array}$ \\
\hline \multicolumn{3}{|l|}{ Rate how well you achieved the following learning goals on a scale of $1-10(1=$ no ability and $10=$ mastery). } \\
\hline Explain the concepts of pumped hydro storage. & 8.7 & 1.0 \\
\hline Explain the concepts of compressed air energy storage (CAES). & 8.5 & 1.3 \\
\hline Explain the concepts of flywheel energy storage. & 7.3 & 1.7 \\
\hline Explain the concepts of thermal (sensible and latent) energy storage. & 7.9 & 1.7 \\
\hline $\begin{array}{l}\text { Formulate and solve real-world problems related to CAES, pumped hyrdro and thermal energy } \\
\text { storage }\end{array}$ & 7.9 & 1.4 \\
\hline Locate and use information and literature associated with energy storage technology. & 7.7 & 1.8 \\
\hline \multicolumn{3}{|c|}{$\begin{array}{l}\text { On a scale of } 1 \text { (none) to } 10 \text { (a great amount), rate how well each of these learning activities contributed to your } \\
\text { foundational knowledge regarding solar thermal energy. }\end{array}$} \\
\hline Readings & 6.4 & 2.4 \\
\hline Lectures by Instructor & 8.5 & 1.0 \\
\hline YouTube Videos & 6.9 & 2.1 \\
\hline Class Discussions & 7.3 & 1.8 \\
\hline Team Project & 7.7 & 1.8 \\
\hline Guest Lecture & 7.9 & 1.6 \\
\hline \multicolumn{3}{|c|}{$\begin{array}{l}\text { On a scale of } 1 \text { (none) to } 10 \text { (a great amount), rate how well each of these learning activities contributed to your ability to } \\
\text { formulate, solve and analyze energy storage problems. }\end{array}$} \\
\hline In-Class Examples & 9.1 & 1.2 \\
\hline Team Project & 7.6 & 1.5 \\
\hline Sample problems with pdf/video solutions & 9.1 & 1.1 \\
\hline \multicolumn{3}{|c|}{$\begin{array}{l}\text { On a scale of } 1 \text { (none) to } 10 \text { (a great amount), rate how well each of these learning activities contributed to your ability to } \\
\text { identify, locate and use sources of information related to solar thermal energy. }\end{array}$} \\
\hline Team Project & 7.3 & 2.1 \\
\hline
\end{tabular}


In addition to the questionnaire, students completed a brief reflective writing assignment at the end of the course. They were asked to answer three questions.

1. Describe a "technical" thing that you found interesting or important in this course.

2. Describe a "non-technical" thing that you found out about yourself as a result of being in this course.

3. Describe one change that you would make to improve the course.

Responses to the first question had little in common. Nearly all of them described a feature of one of the technologies discussed in the course on the foundational knowledge level. Examples included the properties and effectiveness of selective surfaces, information about local projects provided by the guest speakers, and the magnetic bearings used in flywheel energy storage.

Many responses to the "non-technical" question had to do with the human dimension, or working with others. Of the students including human dimension aspects in their response, 9 out of 13 were positive. These typically stated that working with others helped them better understand the material and learn more effectively. Two students (that were on the same team) had negative experiences from a group dynamics standpoint. Three students responses fell into the integration and caring categories, discussing how they better understand the magnitude of the energy challenge and the importance of addressing it.

Finally, several interesting changes were suggested in response to the third question. The most common responses were to arrange a field trip and/or more guest speakers. Several students also suggested that the RATs should be eliminated.

\section{Conclusions}

The significant learning methodology was effective for a senior-level mechanical engineering elective in solar-thermal energy. Conclusions that can be drawn from this experience include:

- The students rated the in-class lectures and examples high compared to the other learning experiences of the course. This was somewhat surprising to the author, who expected some of the less traditional learning activities to be rated highly by the students.

- The readings and RATs were rated low by the students. This could indicate that they were not as effective as anticipated or that the students simply do not enjoy being quizzed every week. However, discussions stemming from the RAT questions were rated highly. One potential problem with the readings is that the level of the journal articles used was too high for undergraduates. Part of the reason that they were selected was to challenge the students, but the challenge may have been too great for some to comprehend on their own. Additionally, a more appealing name might improve student perception of the activity. Overall, when combined with the discussions, they were effective.

- Overall, team activities can be very effective for promoting student learning. However, the risk with this type of activity is high as well, as a minority of students will often have negative experiences.

- The human dimension is a vital aspect of significant learning. Thus, it should be explicitly stated as a learning objective of the course. 
It is difficult to assess the synergy of "rich learning experiences" that combine multiple levels of learning into each activity. However, the overall success of the course and the positive response to the learning activities leads to the conclusion that it is an effective methodology for renewable energy electives.

1. Bloom B. S., Taxonomy of Educational Objectives, Handbook I: The Cognitive Domain. David McKay Co Inc., New York, 1956.

2. Fink, L.D., Creating Significant Learning Experiences: An Integrated Approach to Designing College Courses, John Wiley and Sons, San Francisco, 2003.

3. Michaelson, L.K., Knight, A.B., and Fink, L.D., Team-based Learning: A Transformative Use of Small Groups, Praeger Publishers, Westport, CT, 2002.

4. Fink, L.D., Ambrose, S. and Wheeler, D. "Becoming a Professional Engineering Educator: A New Role for a New Era," Journal of Engineering Education, Vol. 94, No. 1 pp. 185-194, 2005.

5. Apul, D. and Philpott, S., "Use of Outdoor Living Spaces and Fink's Taxonomy of Significant Learning in Sustainability Engineering Education.” Journal of Professional Issues in Engineering Education Practice, Vol. 137, pp. 69-77, 2011.

6. Smith, K.A., Sheppard, S.D., Johnson, D.W. and Johnson, T.J., "Pedagogies of Engagement: Classroom-Based Practices," Journal of Engineering Education, Vol. 94, No. 1, pp. 87-101, 2005.

7. Graff, E.D. and Kolomos, A., "Characteristics of Problem-Based Learning," International Journal of Engineering Education, Vol. 19, No. 5, pp. 657-662, 2003.

8. Building a Sustainable Energy Future: U.S. Actions for an Effective Energy Economy Transformation, National Science Board, NSB-09-55, 2009.

9. Renewable Energy Sources and Climate Mitigation, Intergovermental Panel on Climate Change, Cambridge University Press, Cambridge, England, 2011.

10. Energy for a Sustainable Future - The Secretary-General's Advisory Group on Energy and Climate Change, United Nations, 2010.

11. Tian, Y. and Zhao, C.Y., "A Review of Solar Collectors and Thermal Energy Storage in Solar Thermal Applications,” Applied Energy, Vol. 104, pp. 538-553.

12. Bolund, B., Bernhoff, H. and Leijon, M., "Flywheel Energy Storage and Power Storage Systems," Renewable and Sustainable Energy Reviews, Vol. 11, pp. 235-258, 2007.

13. Reddy, V.S., Kaushik, S.C., Ranjan, K.R. and Tyagi, S.K., "State-of-the-Art of Solar Thermal Power Plants - A Review," Renewable and Sustainable Energy Reviews, Vol 27, pp. 258-273, 2013.

14. Sharma, A., Tyagi, V.V., Chen, C.R. and Buddhi, D., "Review on Thermal Energy Storage with Phase Change Materials and Applications," Renewable and Sustainable Energy Reviews, Vol. 13, pp. 318-345, 2009.

15. Kalogirou, S.A., "Solar Thermal Collectors and Applications," Progress in Energy and Combustion Science, Vol. 30, pp. 231-295, 2004. 